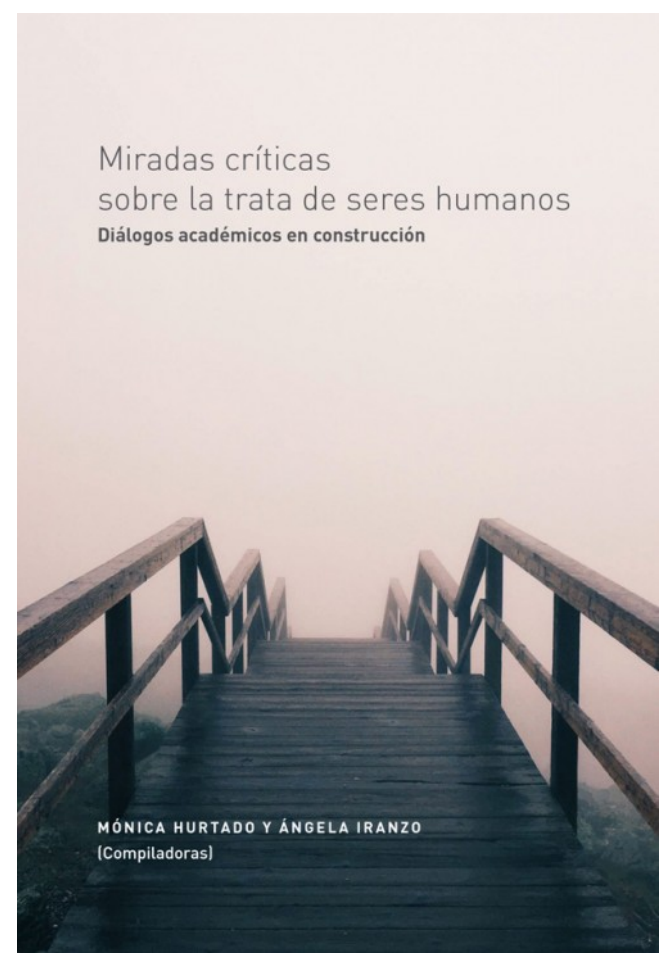

\title{
MIRADAS CRÍTICAS SOBRE LA TRATA DE SERES HUMANOS DIÁLOGOS ACADÉMICOS EN CONSTRUCCIÓN
}

Por: Mónica Hurtado , Ángela Iranzo, Kay Warren, Helga Flamtermensky, Sally Cameron, Edward Newman, Gergana Danailova Trainor, Frank Laczko, Anne Gallagher, Rebecca Surtees, Julia O'Connell Davidson, Elzbieta Gozdziak, Margaret MacDonnell, Niklas Jakobsson, Andreas Kotsadam, Adriana Piscitelli Formato: Impreso

ISBN: 978-958-774-148-3

Facultad: Derecho y Ciencias Políticas

Coeditor: Ediciones Uniandes

Idioma: Español

Precio en dólares: USD $\$ 18,00$

Número de páginas: 300

Palabras clave: Trata de personas, urya

\section{$\$ 55.000$}

\section{Reseña del Producto}

A LA LUZ DE NUEVE ARTíCULOS, en su mayoría escritos originalmente en inglés y traducidos por primera vez al español, Miradas críticas sobre la trata de seres humanos presenta diversos debates y aproximaciones teóricas frente a la trata de seres humanos, no solo en Colombia y en Latinoamerica, sino como un asunto global. Además, lo hace a partir de una revisión crítica de las categorías y los paradigmas que, desde inicios del siglo XX, han venido conformando la interpretación de la trata y de las medidas más adecuadas para combatirla en los ámbitos nacional e internacional.

\section{Información Adicional}

Peso: $1 \mathrm{~kg}$

Tamaño: $17 \times 24 \times 2 \mathrm{~cm}$

Sku: 9789587741483

Código topografico: 364,137

\section{Tabla de contenido}

\author{
AUTORES \\ AGRADECIMIENTOS \\ INTRODUCCIÓN \\ MÓNICA HURTADO \\ ÁNGELA IRANZO \\ I. EL PARADIGMA VÍCTIMA INOCENTE-DEPREDADOR VIOLENTO \\ Capítulo 1
}

Problematizar la dicotomía víctima/tratante en los esfuerzos por combatir la trata de personas

KAY B. WARREN

Capítulo 2 
Descolonizar conocimientos y cuerpos

HELGA FLAMTERMESKY

II. LAS CAUSAS DE LA TRATA: POBREZA, DESARROLLO Y GLOBALIZACIÓN

Capítulo 3

Trata de personas: factores estructurales

SALLY CAMERON Y EDWARD NEWMAN

Capítulo 4

Trata de personas y desarrollo: hacia políticas más coherentes

GERGANA DANAILOVA-TRAINOR Y FRANK LACZKO

III. LA EFICACIA DE LA LUCHA ANTITRATA: LA MEDICIÓN DEL ÉXITO

Capítulo 5

Medición del éxito de las acciones de lucha contra la trata en el ámbito de la justicia penal: ¿quién decide y cómo?

ANNE T. GALLAGHER Y REBECCA SURTEES

IV. LA ESPECIAL PROTECCIÓN DE LA NIÑEZ Y LA ADOLESCENCIA FRENTE A LA TRATA

Capítulo 6

¿Trasladar menores? Trata, migración infantil y derechos de la niñez

JULIA O'CONNELL DAVIDSON

Capítulo 7

Cerrar brechas: la necesidad de mejorar la identificación y los servicios para los niños víctimas de trata de persona ELZBIETA M. GOZDZIAK Y MARGARET MACDONNELL

V. LA RELACIÓN ENTRE TRATA CON FINES DE EXPLOTACIÓN SEXUAL Y PROSTITUCIÓN

Capítulo 8

Derecho y economía de la esclavitud sexual internacional: leyes sobre prostitución y trata con fines de explotación sexual NIKLAS JAKOBSSON Y ANDREAS KOTSADAM

Capítulo 8

Reconsideración de las nociones de trata con fines de explotación sexual y de sus víctimas

ADRIANA PISCITELLI 